\title{
PEDAGOGIA EMPREENDEDORA: UM OLHAR INOVADOR À EDUCAÇÃO BÁSICA
}

\section{ARTIGO ORIGINAL}

VIVONI, Sandra Mara Nunes ${ }^{1}$, SILVA, Ana Carolina Nascimento², SILVA, Leonardo Alexandre $^{3}$, ANDRADE, Sandra Regina ${ }^{4}$

VIVONI, Sandra Mara Nunes. Et al. Pedagogia empreendedora: um olhar inovador à educação básica. Revista Científica Multidisciplinar Núcleo do Conhecimento. Ano. 07, Ed. 01, Vol. 01, pp. 164-179. Janeiro de 2022. ISSN: 24480959, Link de acesso: https://www.nucleodoconhecimento.com.br/educacao/olharinovador, DOI: 10.32749/nucleodoconhecimento.com.br/educacao/olhar-inovador

\section{RESUMO}

Atualmente, o empreendedorismo cresce no Brasil, seja pela falta de cargos para inserção no mercado de trabalho, pela necessidade de fontes adicionais de renda, ou pelo aumento do custo de vida. Incluí-lo como aliado na Educação Básica é uma estratégia que pode permitir formar alunos que se deixam sonhar e não apenas permanecer na passividade. Assim, a questão-problema que norteou este artigo foi: como é a relação do empreendedorismo na Educação Básica? Portanto, este estudo objetivou ampliar a compreensão sobre o tema, analisar a sua situação nesse nível educacional e contribuir com esta temática. Buscou-se, então, um conhecimento da situação atual nas escolas e um modelo de prática de um projeto social empregado por Dolabela (2003; 2008), a "Oficina do Empreendedor", de Manguinhos, RJ, além da valorização da estratégia conhecida como Pedagogia Empreendedora dos

\footnotetext{
${ }^{1}$ Doutorado em Sociologia, Mestrado Multidisciplinar em Desenvolvimento Local, Pós-Graduada em Psicopedagogia e Docência do Ensino Superior, Graduada em Pedagogia. ORCID: https://orcid.org/0000-00019395-1064

2 Pedagoga e MBA em Gestão Empresarial. ORCID: 0000-0002-9098-5821

${ }^{3}$ Graduado em Pedagogia pelo Centro Universitário Augusto Motta - UNISUAM 2019; Pós-Graduado em Gestão empresarial pela AVM. ORCID: https://orcid.org/0000 - 0002-22313054

${ }^{4}$ Bacharel em Serviço Social Universidade do Estado do Rio de Janeiro - UERJ; Graduada em Pedagogia pelo Centro Universitário Augusto Motta - UNISUAM. ORCID: 0000-0001-8789-2600
}

RC: 104728

Disponível em: https://www.nucleodoconhecimento.com.br/educacao/olhar-inovador 
Sonhos. Foram abordados diversos conceitos voltados para o perfil empreendedor, sob diferentes olhares, sobretudo no que se refere à Lei de Diretrizes e Bases da Educação e à Base Nacional Comum Curricular, visando à forma de atuação do docente nas escolas. A metodologia adotada objetivou estabelecer uma análise crítica de estudos sobre o tema, selecionando artigos sobre Pedagogia Empreendedora. Os resultados do projeto pesquisado, que já atendeu mais de 500 jovens desde 2010, demonstram que a maioria já está empreendendo; frequentando ou concluindo a faculdade; ou nas Forças Armadas. Como conclusão, percebe-se que a cultura empreendedora surge como uma educação diferenciada e inovadora que pretende fortalecer a personalidade do aluno para prepará-lo para um mercado dicotômico que demanda um pensamento amplo, universal e uma individualização estimulada pela própria liberdade. E, quanto mais cedo for trabalhada essa questão, com as crianças em sala de aula, mais chances elas terão de se tornarem protagonistas de suas histórias.

Palavras-chave: Educação Básica, Sonho, Empreendedorismo, Protagonismo, Pedagogia Empreendedora.

\section{INTRODUÇÃO}

As constantes mudanças em nossa sociedade resultam cada vez mais na necessidade de empreender. Este artigo busca ampliar o olhar do docente, no universo escolar, a partir da Pedagogia Empreendedora, sendo esta uma estratégia didática para despertar características empreendedoras na Educação Básica. O seu componente inicial é o sonho, compreendido aqui como o objetivo que se quer alcançar e todo o aprendizado construído durante a busca de sua realização. O sonho está voltado para um sonho acordado, capaz de conduzir à autorrealização. Desse modo, a questão-problema que norteou este artigo foi: como é a relação do empreendedorismo na Educação Básica? A metodologia adotada neste trabalho buscou estabelecer uma análise crítica de estudos sobre o tema. Inicialmente foram realizados estudos em livros, na dissertação de mestrado de Vivoni (2009), e em bases de dados, selecionando artigos sobre Pedagogia. Desses, foram escolhidos 0 
de Dias e Mariano (2017); Amorim (2018); Vasconcelos (2019), como referências para este estudo. Desse modo, este estudo teve como objetivos ampliar a compreensão sobre o tema, analisar a sua situação nesse nível educacional e contribuir com esta temática.

Dolabela (2003) defende não existir nada como o sonho para criar o futuro. Aponta, ainda, que o saber empreendedor ultrapassa o domínio de conteúdos científicos técnicos e instrumentais. Estes poucos servem para quem não sonha e para quem não tem a capacidade de, a partir do sonho, gerar novos conhecimentos que produzam mudanças significativas para o avanço da coletividade. Dentro deste contexto, muito se fala em empreender, conquistar, prosseguir... Segundo Dolabela, (2003) o empreendedorismo vem ganhando cada vez mais espaço e importância na Educação Básica brasileira, destacando-se não só na organização e na prática do trabalho pedagógico quanto na formação e especialização profissional dos professores.

O empreendedorismo e o sonho são duas palavras que convergem, entendendo que empreender na era da globalização é uma questão de sobrevivência, de busca da autoestima e da autonomia. Tudo isso está diretamente ligado ao sonho que, por sua vez, é a mola propulsora de todo ser humano. É sabido ainda que o professor precisa estimular, de forma clara e constante, o sonho de seus alunos e desenvolver, a partir das competências, habilidades e atitudes, o que o século XXI exige de um discente.

A finalidade deste artigo, portanto, é ampliar a compreensão sobre o empreendedorismo, analisar a sua situação na Educação Básica e neste contexto contribuir com a atuação desta temática, nos dias atuais, sem pretender esgotar o assunto. Tencionando, assim, a partir de uma revisão bibliográfica, com foco nos autores pesquisados, fazer uma breve reflexão sobre o tema. Na primeira seção, expõe-se a valorização do empreendedorismo e os seus diversos conceitos. Já na segunda, aborda-se a cultura empreendedora nas escolas e, ao longo do texto, sobretudo na terceira seção, como se desenvolve a Pedagogia Empreendedora, servindo de referência à implantação desta prática nas escolas, partindo de uma 
apresentação de fluxograma criado por Vivoni (2009), inspirado na obra de Fernando Dolabela (2003) a respeito da Pedagogia Empreendedora dos Sonhos.

\section{EMPREENDEDORISMO: DIVERSIDADE DOS CONCEITOS}

O empreendedorismo não é um tema novo, pois existe desde as primeiras manifestações inovadoras do homem, que oportunizou a evolução das suas relações com outros homens e a natureza. Sua origem é francesa, "entrepreneur", aquele que assume riscos e começa algo novo. O termo empreendedorismo se refere aos estudos sobre o empreendedor, seu perfil, origens e setor, cujo conceito varia de acordo com a época, o país e a área de atuação. No fim do século XVII, era visto como alguém que fazia qualquer coisa. No fim do século XIX e início do século XX, voltava-se para os donos de indústrias, conforme citado por Dolabela (2003).

Segundo Chér (2008), os empresários e os administradores de empresas não eram valorizados, pelo contrário, a figura do empresário estava relacionada às pessoas ligadas ao poder, que enriqueceram porque deram golpes milionários. Foi a partir da década de 1990 que livros, cursos e palestras voltados ao tema tiraram o empreendedor desta posição, além da grande oferta de serviços. Para isso, o Instituto Empreender Endeavor e o Serviço Brasileiro de Apoio às Micro e Pequenas Empresas (SEBRAE) tiveram participação significativa. Atualmente, o empreendedor está associado à inovação e ao aproveitamento de oportunidades. Não havia o incentivo ao empreendedorismo que hoje se testemunha, conforme ressalta Chér (2008).

O empreendedorismo é uma realidade marcada pelas contradições sociais, pois se vive com maior intensidade um momento no qual o discurso dominante é o de que a sociedade civil organizada deve absorver para si os investimentos sociais historicamente de responsabilidade do Estado. Alega-se incompetência administrativa, a cada dia mais presente na vida dos brasileiros. Tal fato se dá por uma mistura de oportunidades e necessidades, características de um panorama social marcado pelo desemprego e instabilidade de um modo geral. 
Nesse sentido, o empreendedorismo é, por vezes, interpretado como uma forma de crescimento pessoal e individual, cujo único objetivo é empreender para lucro e sustento próprios. É importante ressaltar, no entanto, que o empreendedorismo vai muito além do lucro individual. Primordialmente, ser empreendedor é ter determinados tipos de pensamento e ações que levem à realização. Seu crescimento no Brasil se dá por conta das dificuldades que lesam o país e reduzem oportunidades de ingresso no mercado de trabalho.

Inúmeros são os significados para o empreendedor e, de acordo com as diferentes áreas e domínios de interesse de seus especialistas, tem se definido de diversas formas: para os economistas, como aquele que inova e assume riscos; para os comportamentalistas, a ênfase está nas atitudes, na criatividade, na persistência; na área do Marketing, aqueles que identificam oportunidades. Segundo Dolabela (2003), o empreendedor é o "motor da economia", um agente de mudanças, e defende que ele pode estar em todas as áreas.

De acordo com Dias e Mariano (2017), o empreendedor é aquele que busca sua autorrealização, autonomia e emancipação. Desse modo, precisa ser participante ativo na organização de seu próprio aprendizado, pois só assim desenvolverá as características do homem parentético e empreendedor. Apresenta-se o conceito do homem parentético como aquele que seria capaz de colocar em parênteses sua realidade atual, analisá-la e buscar a solução de problemas da coletividade. Desta forma, realiza não só seus sonhos como também sonhos coletivos. A análise e percepção dessas demandas se voltam para uma participação ativa da sociedade, na escola e do próprio aluno na realidade que o circunda. Portanto, não deve buscar apenas o sucesso pessoal, mas, sobretudo, coletivo.

Os autores afirmam, ainda, que o Brasil engatinha em relação aos países de primeiro mundo quanto ao tempo e investimento no ensino empreendedor. É notório que esse processo é ainda bem limitado, quando falamos da sua implementação na Educação Básica. Um dos principais fatores que interferem neste desenvolvimento do empreendedorismo é a falta de capacitação dos professores que irão atuar nesta modalidade de ensino (DIAS; MARIANO, 2017). 
Atualmente, o empreendedorismo cresce a olhos vistos no Brasil, seja pela falta de cargos para se inserir no mercado de trabalho ou mesmo pela necessidade de outras fontes adicionais de renda, com o aumento do custo de vida. Incluí-lo como aliado na Educação Básica é uma estratégia que pode permitir formar alunos que se deixam sonhar e não apenas obedecer, ou mesmo permanecer na passividade. $O$ desenvolvimento de projetos criativos que busquem realizar os sonhos coletivos de sua comunidade, com a participação da sociedade no ambiente escolar, tem potencial para ser uma mudança bem-vinda ao ensino básico formal brasileiro. No entanto, existem desafios para sua implementação que não devem ser desconsiderados, como a falta de profissionais preparados para tal oportunidade.

Com base nesta concepção, na próxima seção o trabalho se volta para a educação empreendedora, objetivo maior deste artigo.

\section{EMPREENDEDORISMO NAS ESCOLAS}

Esta seção se inicia com a seguinte provocação, visando refletir sobre o tema: Qual a relação do empreendedorismo com a educação? Com base na Lei de Diretrizes e Bases da Educação (LDB) no 9.394, de 20 de dezembro de 1996, em seu título I: "A educação escolar deverá vincular-se ao mundo do trabalho e à prática social", já se percebe nas entrelinhas uma margem para o trabalho com o empreendedorismo. Assim sendo, programas de educação empreendedora têm se apresentado na perspectiva de despertar essa característica, como por exemplo, a Pedagogia Empreendedora, que será discutida ao longo do texto. Tal perspectiva diverge de uma ideia de educação cujo objetivo é formar operários; ao contrário, ela se baseia na ideia de autonomia e liberdade como principais parâmetros.

No Brasil, de acordo com Dornelas (2007), o ensino baseado no empreendedorismo começou a tomar forma na década de 1990, quando entidades como o Sebrae foram criadas. O objetivo de inseri-lo no ensino básico não é, no entanto, visando substituir a educação formal, mas sim adicionar projetos empreendedores às escolas para formar alunos mais preparados para o mercado de trabalho, realizadores e autônomos.

RC: 104728

Disponível em: https://www.nucleodoconhecimento.com.br/educacao/olhar-inovador 
Dolabela, em seu livro Pedagogia Empreendedora (2003), discute a implementação de uma oficina empreendedora nas escolas. Esta foi uma ação preventiva do autor para não deixar reprimir o empreendedor existente em cada ser humano. Para tanto, é importante que o aluno se sinta protagonista do seu processo educacional, desenvolvendo projetos e potencializando sua autoestima. Ainda na mesma obra, Dolabela afirma que o tema central do empreendedorismo deve ser a construção do desenvolvimento humano e social, inclusivo e sustentável. A educação empreendedora deve, assim, incluir necessariamente o aumento da capacidade de gerar capital social e capital humano.

A priori, destaca-se principalmente o papel da escola na formação básica, pois é por meio desta que o ensino empreendedor é capaz de aguçar a criatividade e a escolha do desenvolvimento do sujeito, tornando-o capaz de usufruir do meio e de suas particularidades para o avanço social e econômico de todos, como diz Amorim (2018).

Neste contexto, ensinar empreendedorismo significa formar pessoas com senso de liderança, resiliência na solução de problemas, experiência de trabalho em equipe e a capacidade de se reinventar, adaptar-se ou se transformar em qualquer cenário. À vista disso, a escola é o ambiente ideal para desenvolver esta habilidade de empreender, uma vez que acompanha o crescimento do indivíduo e seguem conjuntamente com isso as habilidades socioemocionais, cognitivas, comportamentais, como a própria liderança, empatia, responsabilidade social, ética e controle emocional das situações.

A cultura empreendedora está presente na vida do ser humano desde o seu nascimento, ocorrendo a necessidade de uma busca por uma oportunidade de crescimento e ações inovadoras, e tais transformações serão alicerces para a Educação Empreendedora nas escolas. Dornelas (2007) reitera que o bom empreendedor seria um administrador completo, visualizando as diversas abordagens existentes, sem se limitar em parar na primeira dificuldade, e interagindo com o meio para a tomada da melhor decisão e levanta, ainda, questionamentos de que o empreendimento não é herança genética, e que pode ser ensinado. 
Já Dolabela (2003) defende que a educação empreendedora não pode ser ensinada, mas pode ser aprendida, desde que haja um ambiente favorável a este aprendizado. No Brasil, desenvolve-se uma estratégia educativa voltada ao estímulo dos sonhos e suas realizações, denominada Pedagogia Empreendedora que, para o autor, deve ser inserida na Educação Básica e até no nível superior, visto que incentiva a cultura social e desperta e fortalece as pessoas em nossa sociedade.

Analisando o cenário contemporâneo, a prefeitura de São José dos Campos, interior do São Paulo, aplica a teoria da Pedagogia Empreendedora dos Sonhos em 27 escolas da educação básica, tendo como objetivo despertar na criança o desejo de ser protagonista do próprio futuro. Projetos são expostos em feiras lúdicas e didáticas que permitem trabalhar valores humanos, contribuindo também com a formação de caráter de cidadãos íntegros, com uma qualidade de vida melhor (DOLABELA, 2003).

Como exemplo de mais um trabalho sobre educação empreendedora no âmbito social, há no Rio de Janeiro um projeto em prol da comunidade de Manguinhos, chamado "Oficina do Empreendedor", que tem como objetivo principal despertar características empreendedoras nos jovens de 14 a 21 anos nos níveis individual, organizacional e social, investindo na autoestima, desenvolvendo o senso crítico reflexivo, privilegiando os valores humanos e a responsabilidade social. Este projeto já atendeu mais de quinhentos participantes, desde a sua fundação, em 2010, com alunos como jovens aprendizes; frequentando ou já concluindo a faculdade; nas Forças Armadas; que abriram seus pequenos negócios; alguns casados e com filhos. O trabalho está voltado para o perfil empreendedor, usando como referência o conteúdo do livro "Oficina do Empreendedor", de Dolabela (2008).

Na obra de Dolabela "Pedagogia Empreendedora" (2003), faz-se uma referência ao relatório da UNESCO da Comissão Internacional sobre Educação para o século XXI, com os quatro pilares da educação", que são: aprender a aprender; aprender a fazer; aprender a conviver; e aprender a ser. $\mathrm{O}$ autor insere um quinto pilar, voltado para o empreendedorismo, chamado: aprender a empreender. 
Neste cenário, o documento da Base Nacional Comum Curricular (BNCC) foi homologado pelo Ministério da Educação (MEC), em sua terceira versão, no dia 20 de dezembro de 2017, para as etapas da Educação Infantil e Ensino Fundamental; e, em 14 de dezembro de 2018, para a etapa do Ensino Médio. Juntas, as Bases da Educação Infantil, Ensino Fundamental e Ensino Médio integram um único documento: a BNCC da Educação Básica, um guia que serve aos currículos de todas as escolas do país. Nas competências estão as diretrizes, relacionadas à educação socioemocional, que está conectada de alguma maneira, à Pedagogia Empreendedora dos Sonhos, como, por exemplo:

[...] Argumentar com base em fatos, dados e informações confiáveis, para formular, negociar e defender ideias, pontos de vista e decisões comuns que respeitem e promovam os direitos humanos e a consciência socioambiental em âmbito local, regional e global, com posicionamento ético em relação ao cuidado de si mesmo, dos outros e do planeta.

Conhecer-se, apreciar-se e cuidar de sua saúde física e emocional, reconhecendo suas emoções e as dos outros, com autocrítica e capacidade para lidar com elas e com a pressão do grupo;

Exercitar a empatia, o diálogo, a resolução de conflitos e a cooperação, fazendo-se respeitar e promovendo o respeito ao outro, com acolhimento e valorização da diversidade de indivíduos e de grupos sociais, seus saberes, identidades, culturas e potencialidades, sem preconceitos de origem, etnia, gênero, idade, habilidade/necessidade, convicção religiosa ou de qualquer outra natureza, reconhecendo-se como parte de uma coletividade com a qual deve se comprometer.

Agir pessoal e coletivamente com autonomia, responsabilidade, flexibilidade, resiliência e determinação, tomando decisões, com base nos conhecimentos construídos na escola, segundo princípios éticos democráticos, inclusivos, sustentáveis e solidários. (BNCC, 2019, pp. 9-10)

A BNCC aponta a necessidade de que os alunos sejam capazes de utilizar os saberes que adquirirem para colocar em prática no seu dia a dia, sempre respeitando princípios universais, como a ética, os direitos humanos, a justiça social e a sustentabilidade ambiental. Ela também sugere que as escolas promovam não apenas o desenvolvimento intelectual, como também o social, o físico, o emocional e o cultural, compreendidos como dimensões fundamentais para perspectiva de uma educação integral. 
Dolabela (2003) ainda indica a presença de alguns comportamentos, que serão abordados na próxima seção, chamados pelo autor de elementos de suporte necessários ao empreendedor de sucesso, e a emoção que traz à tona as características empreendedoras na busca e realização dos sonhos que conduzam à construção do saber empreendedor.

\section{A ATUAÇÃO DA PEDAGOGIA EMPREENDEDORA DOS SONHOS}

Todo ser humano é capaz de ser o protagonista da sua própria história, ao desenvolver características tais como mudar, transformar, crescer e evoluir, ou seja, o trabalho coletivo como ponto inicial é base para a atuação das crianças na educação empreendedora.

A Pedagogia Empreendedora, na visão de Dolabela, é uma forma de incentivar o sonho de diversas formas. Saber como trabalhar com o aluno e como levar as formas prazerosas de fazer este educando aprender a apreender e saber fazer é um desafio para o professor. Para tal, é importante, enquanto líder, que o professor ajude o outro - a criança - a seguir seus sonhos, a imaginar, criar, inovar, fazendo isto de forma contínua, levando emoção e ajudando-a a chegar a este tão almejado sonho. Dolabela ainda defende que líder é "alguém capaz de convencer seus colaboradores de que podem chegar a um ponto de futuro favorável para todos e que conhece um meio pra isso". (DOLABELLA, 2003). Posto isso, o líder - professor - sabe orientar exatamente seu aluno para concretizar seu sonho de forma empreendedora.

No nosso atual cotidiano, o empreendedorismo está ligado a uma forma de combate ao desemprego. Com a globalização, o espírito de empreender e realizar o sonho de ter o próprio negócio aumentou de forma contínua. O que nos volta para a sala de aula, onde o professor tem seu papel de líder e a levar seus alunos para uma autorrealização, cujo objetivo primordial da pedagogia empreendedora está em estimular os alunos e prepará-los para sonhar e buscar sua realização, como também desenvolvê-los e torná-los capazes de sonhar e praticar os diversos saberes.

RC: 104728

Disponível em: https://www.nucleodoconhecimento.com.br/educacao/olhar-inovador 
Encontram-se na Pedagogia Empreendedora dos Sonhos sugestões de como oferecer meios para construção dos sonhos dos alunos, a partir de conversas informais ou entrevistas, incentivando-os, trabalhando, sempre que necessário, com diversos recursos como jogos, teatro, simulação, exercícios, entre outros, de maneira que todo este movimento seja registrado num "mapa do sonho", um caderno para que seja acompanhado pelo aluno o processo de busca do seu sonho, levando à reflexão de seus atos, sua determinação e sobre o resultado disto para a sua vida pessoal, acadêmica e profissional.

O sonho e o emocional de uma criança são termos que caminham simultaneamente, pois as emoções podem alterar qualquer cenário. O livro "O líder em mim: Como escolas ao redor do mundo estão inspirando grandeza", de Hatch et al. (2017), valoriza um lado familiar afável, assim o desenvolvimento da criança estará bem desenvolvido no âmbito escolar.

No cenário atual o sonho pode ser desenvolvido a partir de um treinamento eficaz para o aprendizado de liderança e as competências fundamentais para o sucesso na escola e na vida. Observou-se isso, de forma empírica, em algumas instituições escolares, como exemplo o Colégio PH, situado no Maracanã, no Rio de Janeiro, que adaptou seu Projeto Político Pedagógico relacionando-o ao livro "Os 7 hábitos de pessoas mais eficazes", em que a criança vai em busca de seu sonho (metas), fazendo relação com as competências do século XXI.

Quanto mais cedo o empreendedor decidir o que deseja ser e fazer, mais chances terá de sucesso, pois mais chances terão de modificar as atitudes adequadas ao sucesso. (VASCONCELLOS, 2019).

Ao aprender princípios como "seja proativo", "pense ganha-ganha" e "faça primeiro o mais importante", os discentes tornam-se mais autoconfiantes e independentes e passam a adotar novas atitudes, não apenas na escola, mas também com a família e na comunidade. 
Dolabella (2003) afirma que o sonho individual na concepção é o sonho fortemente influenciado pelo ethos da comunidade a que pertence o sonhador, e, com isso, o sonho coletivo vem com a finalidade de necessariamente oferecer (e não subtrair) valor para a comunidade. Levando em conta o contexto atual, o ato de despertar Competências, Habilidades e Atitudes ( $\mathrm{CHA}$ ) nos alunos é um passo grande para a busca de suas metas (sonhos) e a referência dos 7 hábitos para despertar características empreendedoras nos alunos nas escolas. O líder exerce um papel importante na caminhada dos sonhos, lembrando que o protagonista do seu sonho é o aluno, e o líder irá nortear os saberes para que haja o sucesso, ou seja, a realização do seu sonho. Esta prática nas escolas pode contribuir com as demandas da nossa sociedade.

$\mathrm{Na}$ proposta da Pedagogia Empreendedora dos Sonhos é desenvolvido, inicialmente, por parte do aluno, um sonho, um futuro em que deseja chegar, estar ou ser. Depois, ir à busca deste sonho, torná-lo concreto e, para isto, o aluno se vê motivado a aprender o que for necessário para realizá-lo. A busca constante do sonho serve como manutenção emocional, dando ao discente a vontade de persistir e aprender com os erros, apesar dos obstáculos que poderá enfrentar. Leva à necessidade de saber, conhecer, fazer, ser e conviver, e este conhecimento é considerado por Dolabela (2003) como saber empreender, partindo do contexto da realização de desejos e, consequentemente, de prazer; e, referindo-se à aprendizagem significativa, cuja atividade pedagógica vai se voltar para o sonho e sua realização (DOLABELA, 2003), além das perguntas: "Qual é o seu sonho e como você vai realizá-lo?". A figura 1 a seguir apresenta a representação objetiva da Pedagogia Empreendedora dos Sonhos em sua prática. 
Figura 1. Fluxograma Da Implementação Da Pedagogia Empreendedora

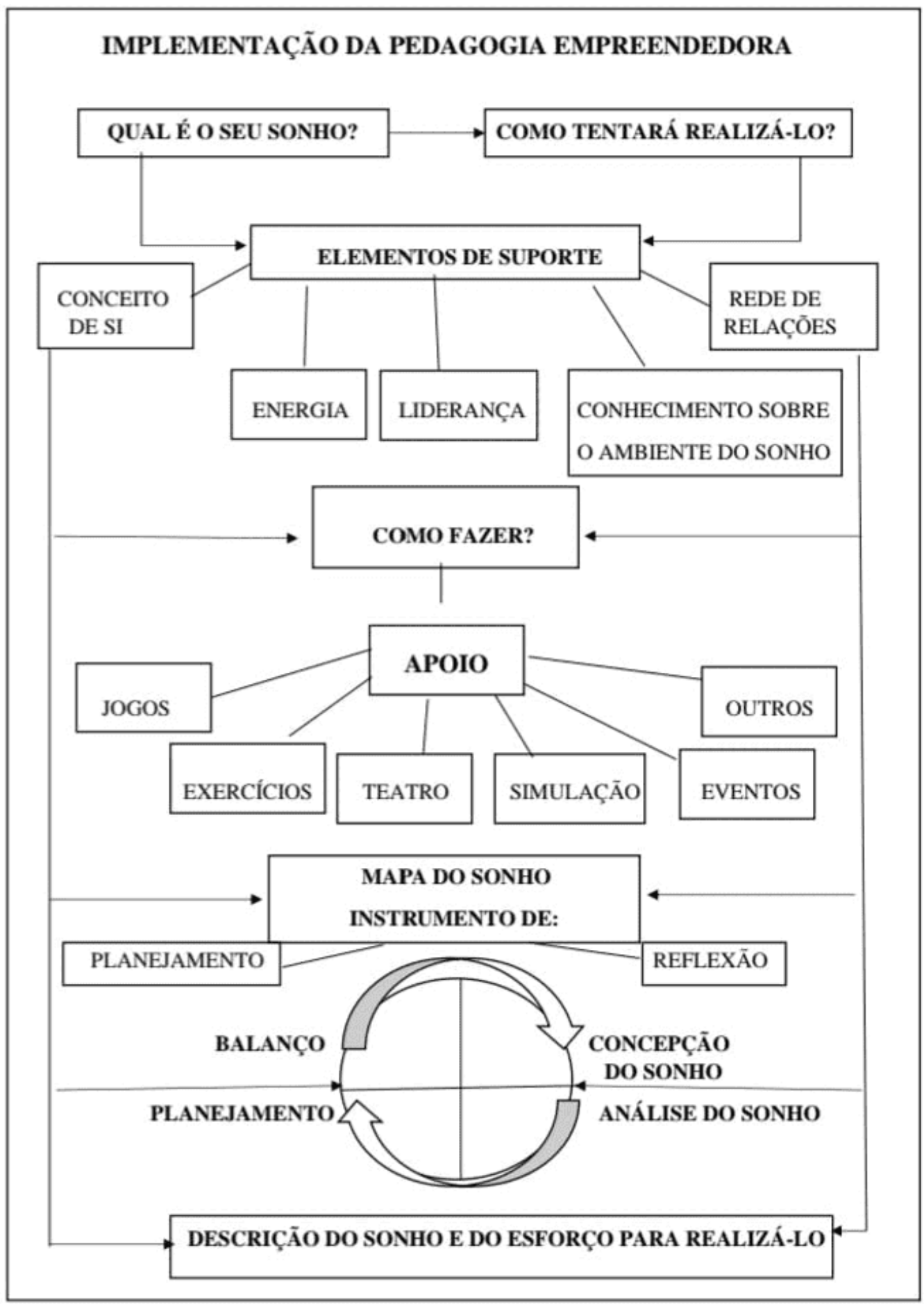

Fonte: VIVONI. S.M.N, 2009.

O fluxograma propõe, como é possível observar, a conexão entre sonhar e buscar realizar o sonho, visualizando-se os elementos de suporte: conhecimento de si

RC: 104728

Disponível em: https://www.nucleodoconhecimento.com.br/educacao/olhar-inovador 
(conhecimento das forças e fraquezas), energia ( disposição para ir em busca do sonho), liderança (poder de persuadir o outro em prol do seu sonho), conhecimento de setor (construir conhecimentos no processo de busca do sonho) e rede de relação (busca de pessoas que contribuam com a realização dos seus sonhos), traços que sustentam o empreendedor.

O sonho está presente em nossa vida em todos os instantes: no trabalho, nos horários vagos, nas férias, na aposentadoria. Ou seja, é permanente: a todos os momentos, o sonho poderá ser imaginado e realizado (VASCONCELLOS, 2019).

\section{CONSIDERAÇÕES FINAIS}

O presente artigo pretendeu verificar como é a relação do empreendedorismo na Educação Básica, além de objetivar trazer contribuições ao entendimento do fenômeno da Pedagogia Empreendedora, que registra o fato de que o saber empreender é um aprendizado contínuo, que está sendo realizado e que precisa ser evidenciado nas escolas. A cultura empreendedora surge como uma educação diferenciada e inovadora que pretende fortalecer a personalidade do aluno no sentido de prepará-lo para um mercado dicotômico que demanda, ao mesmo tempo, um pensamento amplo e universal e uma individualização estimulada pela própria liberdade. Porém, conclui-se que ainda há muito a ser feito para que a Prática Pedagógica Empreendedora seja atuante dentro das escolas e, sobretudo, que faça parte do Projeto Político Pedagógico das unidades de ensino, viabilizando a construção de um novo olhar para todos.

Percebe-se que a educação empreendedora não tem intenção de substituir a educação regular, pois a sua função nas escolas é de formar pessoas que possam definir seus próprios caminhos. E, assim, é possível educar os sujeitos simplesmente para o desenvolvimento do homem operacional, cujo objetivo é, basicamente, o ajustamento ao contexto do trabalho e não crescimento pessoal; educar, também e, sobretudo para desenvolver o homem parentético, ou seja, educar para que os indivíduos desenvolvam a capacidade de colocar as circunstâncias ou sua realidade 
entre parênteses, analisá-las, propor mudanças e transformar sua própria realidade, seu contexto social.

Sendo assim, quanto mais cedo for trabalhada essa questão, com as crianças em sala de aula, mais chances elas terão de realizarem seus sonhos e de se tornarem protagonistas de suas histórias.

\section{REFERÊNCIAS}

AMORIM, Djanine Almeida. A Pedagogia Empreendedora na Educação Básica Brasileira. Revista Científica Multidisciplinar Núcleo do Conhecimento. São Paulo, Ano 03, Ed. 03, Vol. 03, pp. 14-45, Março de 2018. Disponível em: $<$ https://www.nucleodoconhecimento.com.br/educacao/pedagogia-empreendedora $>$. Acesso em: 24 ago. 2021.

BRASIL. BASE NACIONAL COMUM CURRICULAR. [S. I.], 2017. Disponível em: ,http://basenacionalcomum.mec.gov.br/images/BNCC_EI_EF_110518_versaofinal_si te.pdf.. Acesso em: 18 set. 2019.

. Lei o 9.394, de 20 de dezembro de 1996. Estabelece as diretrizes e bases da educação nacional. Brasília, DF, dez. 1996. Disponível em: <http://www. planalto.gov.br/ccivil_03/leis//9394.htm>. Acesso em: 22 ago. 2021.

CHÉR, Rogério. Empreendedorismo na Veia: Um Aprendizado Constante. $1^{\text {a }}$ Edição. Rio de Janeiro: Ed Campus Elsevier, 2008. 248p. ISBN: 9788535274103.

HATCH, David K. ; SUMMERS, Muriel; COVEY, Stephen; COVEY, Sean. $O$ líder em mim: Como escolas ao redor do mundo estão inspirando grandeza. 1a Edição. São Paulo: Editora Benvirá,. Isbn: 8557171382, 2017, 336 p.

DIAS, Bruno Francisco Batista; MARIANO, Sandra Regina Holanda. Educação Empreendedora na Educação Básica e o Homem Parentético de Guerreiro Ramos. Cadernos de Gestão e Empreendedorismo , [S. I.], p. 55-66, 6 jul. 2017. Disponível em: 
https://www.researchgate.net/publication/330640771_Educacao_empreendedora_na _educacao_basica_e_o_homem_parentetico_de_Guerreiro_Ramos. Acesso em 13 maio 2021.

DOLABELA, Fernando. Oficina do Empreendedor. 1a. Edição. Rio de Janeiro: Sextante, 2008, 320p., ISBN 978-85-7542-403-2.

DOLABELA, Fernando. Pedagogia Empreendedora. 1‥ edição. São Paulo: Editora De Cultura, 2003, 140 p., ISBN: 9788589759014.

DORNELAS, José Carlos. Empreendedorismo na Prática: Mitos e Verdades do Empreendedor de Sucesso. 3ạ. Edição. Rio de Janeiro: Ed. LTC, 2015, 180p., ISBN 8521627920.

VASCONCELOS, Flávio José Nelson de. Pedagogia Empreendedora. Revista Construir Noticias. Curitiba, ed. 42. Disponível em: ,http://www.construirnoticias.com.br/pedagogia-empreendedora-2/.. Acesso em: 24 ago. 2019.

VIVONI, Sandra Mara. A Questão da Identidade Social e Política da Pedagogia Empreendedora no Desenvolvimento Local: Ressignificando Competências Através da Educação. 2009. Dissertação de mestrado em desenvolvimento local.

Enviado: Dezembro, 2021.

Aprovado: Janeiro, 2022. 